Article

\title{
Angry and Alone: Demographic Characteristics of Those Who Post to Online Comment Sections
}

\author{
Michael Artime \\ Department of Politics \& Government, Pacific Lutheran University, 12180 Park Avenue South, Tacoma, \\ WA 98447, USA; artimemr@plu.edu; Tel.: +1-509-279-8979 \\ Academic Editor: Terri Towner \\ Received: 30 June 2016; Accepted: 18 October 2016; Published: 26 October 2016
}

\begin{abstract}
The Internet and social media afford individuals the opportunity to post their thoughts instantaneously and largely without filters. While this has tremendous democratic potential, it also raises questions about the quality of the discourse these technological changes portend. Online comment sections may be a particularly unique form of communication within social media to investigate because of their ubiquitous and often anonymous nature. A longitudinal examination of Pew Center data over the course of 4 years suggests that there are demographic differences between people who post and those who do not post to online comment sections. Specifically, in 2008 and 2010 regression analysis demonstrates there is an increased likelihood of posting among men, the unmarried, and the unemployed. However, the 2012 data tells a different story and suggests the possibility that the nature of comment sections might be changing. The findings have important implications for understanding the character of online discourse as well as the vitriol undergirding the political attitudes of disaffected citizens.
\end{abstract}

Keywords: social media; new media; internet; political participation; civic participation; elections; campaigns; politics; mass media

\section{Introduction}

In a 2011skit, the popular sketch comedy show, Saturday Night Live, portrayed a conversation between individuals who post to online comment sections and the objects of their scorn. This is a brief interaction between the fake show's host, Jeff (played by Jason Sudeikis) and a prolific commenter with strong political attitudes, Jennifer Evans (played by Melissa McCarthy):

Jeff: Our final guest is Jennifer Evans, AKA DaTruf! [mocking] DaTruf. Now, Jennifer, your comments focus mostly on promoting your political agenda, correct? Uh, for example, under a video of a bear falling out of a tree onto a trampoline, you wrote: "Obama is our first Nigerian President!"

Jennifer Evans: Yeah! I did. Yeah.

Jeff: And under a clip of a bride tripping and falling into her own wedding cake, you wrote: "No more illegals. Illegals SUUUUUCK"!

Jennifer Evans: [annoyed] Yeah, Jeff, that's what I said!

Jeff: Alright, let's see...Under a video tribute to the late Gene Siskel, you wrote: "9/11 is inside job".

Jennifer Evans: Yeah. Yeah. I sure did [1].

Comment sections are forums attached to the conclusion of online news stories or blog posts and are designed to increase audience interactivity with the content contained in said stories. These forums 
have become a staple of online news sites and, as such, represent an important and understudied place of democratic deliberation.

While these forums were designed for civil debate, online commenters are certainly not viewed as the second coming of Lincoln and Douglas. The caricature of online commenters in popular culture often matches up with our own personal experiences visiting these forums. The assumption is that the individuals responsible for the often vitriolic dialogue online must have serious interpersonal and intellectual problems. This characterization, however, is an assumption that has not been rigorously tested.

A prior study using focus groups to explore online behavior illuminated some interesting thoughts about online comment sections and those that routinely post their own comments on these forums. While some of the respondents acknowledged finding helpful links or opinions in the comment sections of news stories, they did not express personal experience or interest in posting themselves. Perhaps this was a result of their negative attitudes toward those who post. Some descriptions used by participants for those who write the comments at the end of news articles included: "unreliable and almost uninformed", "loud", "they are hiding behind technology...[I] feel sorry for them that they have to hide behind technology" [2].

The anecdotal discussion of commenters assumes that their posting is not part of a broader strategy of political participation, but rather an outlet for a disaffected class of individuals who are unlikely to have meaningful personal or political relationships offline.

This paper will attempt to answer two important questions. First, do those who post to online comment sections attached to political news articles match the isolated, angry picture ascribed to them in popular culture? Second, how are these commenters involved in politics apart from the comment sections? Ultimately, this study hopes to provide a more complete picture of a growing group of individuals leading a substantial number of the political debates and dialogues occurring in American politics.

Likewise, the paper will be situated in a larger discussion about the role of the Internet in shaping political attitudes and behaviors. There are some who believe that the Internet is a great, democratizing force that provides a voice to those traditionally marginalized by the rich and powerful in American politics. Others believe that the Internet is serving to exacerbate some of the most negative elements of American politics-vitriolic language, elite control, and prejudice. Rigorous examination of comment sections is an important addition to this ongoing debate.

\section{Literature Review}

The discussion of comment sections is situated in a larger body of literature evaluating the consequences of Internet news on civic and political participation and efficacy. While advancements in technology are ongoing, scholars have been discussing new media for quite some time. Indeed, Castells presciently argued in 1989 that technological advances and, in part, advances in communication were "transforming the material basis of our lives" [3]. Generally, most scholars who have looked at online news agree that, in terms of content, online political information is more negative in tone relative to mainstream news sources [4]. Likewise, some of the literature suggests that this negativity is produced through an "echo chamber" in which the loudest, most hostile voices are amplified in a way decidedly different than in the offline political environment [5]. A striking example of this can be found in Hassell and Week's 2016 study which found that online partisan media has, for users, the ability to generate anger against their opposing party and compel them to express that anger through various online tools [6]. Hwang, Kim, and Huh argue that these uncivil online conversations can lead to a broader crisis whereby individuals perceive "that issue attitudes among the mass public are more deeply polarized along party lines than those who were exposed to civil discussion" [7]. Perhaps these trends help us explain why Lelkes et al. found that increasing broadband in a community corresponded with an increase in partisanship and hostility in that community [8]. 
Likewise, there is some skepticism regarding the presumed democratic nature of the Internet as a forum for political engagement [9]. Correspondingly, Hindman suggests that the Internet is still, by and large, controlled by elites and is not the anecdotal ground-up, unfiltered forum sometimes described [10]. Additionally, Wellman et al. propose that the individuals who use the Internet most are also those who are the least interested in fostering a sense of online community [11]. These findings would suggest that there is little interest among heavy users in retaking online community from the elites who are purportedly running the show at the moment. However, even if it is granted that the Internet is negative and controlled by elites, this is not necessarily evidence for the proposition that the Internet is bad for civic engagement.

For example, Boulianne uses a meta-analysis of 38 studies to demonstrate that the Internet does not suppress engagement and, in fact, online news serves to reduce barriers for those wanting to become more involved politically [12]. Mossberger finds that there is some degree of increased communication between citizens and those in government-adding the caveat that most of these interactions consist of the government "pushing" their agenda on their constituents [13]. Likewise, Tedesco provides evidence to suggest that negative media did not appear to shake the political efficacy of young Democrats in the 2008 presidential election [14].

In order to more fully understand the dynamics of online news, it is essential to isolate the unique features that make it distinct from traditional forms of media. For example, online news offers a degree of interactivity to users that would be impossible for even the most ardent writer of letters to the editor in a local paper. In particular, online comment sections afford users the ability to immediately, and often anonymously, respond to any news item for which they have an opinion. Freelon argues that "commenters use facts and questions to substantiate their points with non-deliberative personal attacks, a curious juxtaposition that might be called 'deliberative individualism'" [15]. Rosenberry effectively demonstrates that this deliberative individualism is something that users understand and even want to protect [16]. Specifically, users of newspaper comment sections point the finger at the anonymous nature of these forums as being to blame for the negativity and rude comments. However, these same users do not desire a change from this anonymity. Rowe examined both the Washington Post Facebook page as well as the Post's website comment sections and found that incivility was more prevalent in the comment sections. Rowe argues that the anonymity of the website's forums were critical in creating this difference [17]. Negativity is further encouraged by the fact that, if users want their comment to generate additional conversation, then that comment should be controversial [18].

Frequent posters, according to Blom et al., are more likely to act in uncivil and less deliberative ways [19]. Additionally, this negativity can snowball, according to Rösner and Krämer, who posit that aggressive comments online only serve to change the understood ground rules of comment sections thus opening the door to a new, more vitriolic dialogue [20]. This is particularly troubling, as noted by Hsueh et al., in the domain of prejudiced attitudes and behaviors. In their work they suggest that prejudiced comments serve to produce additional prejudiced comments. However, the implications are not simply limited to online discussion as the author's note that these prejudicial statements serve to shape offline attitudes and behaviors [21].

Likewise, there is good evidence that these forums serve to replicate power differentials and hierarchies that exist offline-increasing hostility to marginalized gender and racial groups [22,23]. Also troubling is the evidence that it can be difficult, particularly for young people, to evaluate the credibility of the information that they receive online [24-27]. If this is the case, then the content produced through these comment sections is perhaps conflated with content from objectively more credible sources.

While much of the scholarship is skeptical about the potential benefits of comment sections, there is some research which cautions us against assuming the worst about these forums. Hoffman, for example, posits that these forums present an opportunity for citizens to add their voice to political debates. Likewise, she suggests that online comments are not fundamentally different than the content of our offline political discussions [28]. Additionally, there is some evidence that innovation can curb 
some of the more abusive, hostile language in these comment sections. For example, Singer argues that the Guardian was successful in providing "carrots" to commenters in order to encourage rational debate. Comment sections then served the role of keeping reporters honest-they knew that factually inaccurate, lazy reporting would be met with quick rebuttals from the online community [29]. Graham and Wright also examine the Guardian and note that journalists spoke positively about the role of online forums in aiding their reporting [30].

In sum, much of the existing research has shown that comment sections are appealing because of their anonymous nature and the built-in incentives for posting negative, uncivil content. Likewise, comment sections can shape the way that their readers understand the political world and their place in it. However, very little attention has been paid to the demographic characteristics of those who have chosen to use these forums as a means of sharing their questions, attitudes, and their insults. This is problematic because these are the individuals leading important political conversations throughout the country. This paper is an attempt to draw a more complete, nuanced picture of commenters.

\section{Method and Materials}

In order to get this more complete picture of the individuals most likely to use online comment sections, I have examined a series of surveys conducted by the Pew Research Center. The surveys were conducted in 2008, 2010, and 2012 and ask a series of questions related to Internet use and political activity [31-33]. The Pew Center has been tracking online political behavior for some time and provides a great source of data for those interested in studying the intersection of media and political attitudes and behaviors. The purpose of this paper is to examine demographic predictors for posting to online comment sections and, as such, each regression will use posting as a dependent variable and a range of different demographic characteristics (age, gender, income, education, party identification, marital status, employment, parental status, race, and religion) as independent variables. Logistic regressions are used because the dependent variable is binary. Likewise, regression analysis is preferable to cross-tabulation because it allows us to isolate the unique relationship between various demographic characteristics and commenting. Included in this analysis, is the question as to how involved politically are those who post to these comment sections.

More detailed descriptions of the variables used for each of the analyses can be found in Appendix A.

\section{Results}

According to the 2008 Pew Center data only 11\% of individuals claimed to comment on a website of any kind [32]. This study assessed the relationship between endorsing ever commenting on a website and a wide variety of demographic variables including age, gender, political affiliation, education, race, religiosity, employment status, marital status, and parent status (see Table 1). Logistic regression analyses were used to empirically test whether these demographic variables predicted commenting history. The following table depicts the standardized coefficients of each of the demographic variables in the logistic regression model.

The dependent variable is a binary variable where 1 indicates that the respondent did comment on a web site and 0 indicates that the respondent did not comment on any web sites. The logistic regression indicates that gender, employment status, and marital status are statistically significant in determining whether or not the respondent posted a comment on a web site. In terms of gender, men were $4 \%$ more likely to post online comments compared to women. Specifically, approximately $14 \%$ of men claimed to post online comments, but $10 \%$ women have posted. Additionally, for married individuals the probability of posting online comments was roughly $7 \%$ lower than for unmarried respondents, 16\% and 9\% respectively. Finally, being employed decreased the likelihood of posting by approximately $11 \%$. Unemployed individuals had a predicted probability of posting of roughly $21 \%$. 
Table 1. Logistic regression evaluating which individuals are most likely to post online comments in 2008 (Pew Internet \& American Life Project [32]).

\begin{tabular}{lc}
\hline Independent Variables & Coefficient (Standard Errors) \\
\hline Age & $-0.09(0.08)$ \\
Gender & $0.47(0.21)^{*}$ \\
Married & $-0.64(0.24)^{* *}$ \\
Parent & $-0.12(0.24)$ \\
Employment & $-0.86(0.27)^{* *}$ \\
Republican & $-0.08(0.27)$ \\
Democrat & $0.38(0.25)$ \\
Religious Attendance & $0.05(0.06)$ \\
Education & $0.10(0.08)$ \\
Race & $-0.15(0.30)$ \\
Income & $0.08(0.06)$ \\
Constant & $-1.98(0.59)^{* *}$ \\
\hline Model Summary Statistics & \\
Number of Observations & 970 \\
Pseudo R-Squared & 0.04 \\
Log Likelihood & -345.00 \\
\hline
\end{tabular}

Notes: The dependent variable is a binary variable where 1 indicates that the respondent did comment on a website and 0 indicates that the respondent did not comment on any website; $\mathrm{N}=970,{ }^{*}=p<0.05,{ }^{* *}=p<0.01$.

Evaluating the way in which the significant predictors interact is also fruitful for arriving at a more developed understanding of commenters. Specifically, for men who are unemployed the likelihood that they will select to post online comments is approximately $25 \%$. However, for those same individuals, if they are also unmarried the odds increase to roughly $33 \%$. This contrasts starkly with men who are employed and married who have a likelihood of posting of only $10 \%$.

In order to determine whether or not these trends hold true over time the 2010 Pew Center data was evaluated. Similarly, a logistic regression model was used to test the impact of demographic variables on commenting history. Table 2 describes the results of these analysis.

Table 2. Logistic Regression evaluating which individuals are most likely to post online comments in 2010 (Pew Internet \& American Life Project [31]).

\begin{tabular}{lc}
\hline Independent Variables & Coefficient (Standard Errors) \\
\hline Age & $-0.00(0.00)$ \\
Gender & $0.37(0.13)^{*}$ \\
Satisfied & $-0.15(0.14)$ \\
Married & $-0.29(0.14)^{*}$ \\
Parent & $0.24(0.15)$ \\
Employment & $-0.32(0.16)^{*}$ \\
Republican & $-0.24(0.16)$ \\
Democrat & $0.03(0.16)$ \\
Education & $0.04(0.04)$ \\
Race & $-0.16(0.17)$ \\
Income & $-0.00(0.00)$ \\
Constant & $0.77(0.32) *$ \\
\hline Model Summary Statistics & \\
Number of Observations & 1441 \\
Pseudo R-Squared & 0.02 \\
Log Likelihood & -786.80 \\
\hline
\end{tabular}

Notes: The dependent variable is a binary variable where 1 indicates that the respondent did comment on a website and 0 indicates that the respondent did not comment on any website; $\mathrm{N}=970,{ }^{*}=p<0.05,{ }^{* *}=p<0.01$. 
The pattern of results is almost identical in 2010. The dependent variable is again binary where 1 signifies that the respondent posted a comment on an online news article and 0 suggests that the respondent did not post a comment. ${ }^{1}$ The data indicate that $24 \%$ of the respondents claimed to post a comment online. Once again, the regression indicates that the gender, marital status, and employment status of the respondent are important indicators of whether or not they posted a comment on an online news site. With regard to gender, the predicted probability of a man posting an online comment was approximately $7 \%$ greater than for women. More specifically, men had a predicted probability of $28 \%$. Additionally, being married decreased the predicted probability of posting by approximately $5 \%$. Unmarried individuals had a predicted probability of posting of around 27\%. Finally, being employed decreased the probability of posting by about $6 \%$ relative to those who were unemployed. Unemployed individuals had a predicted probability of posting of approximately $29 \%$.

When examining the intersection of multiple demographic identities, the likelihood of an unemployed man posting a comment online was approximately 33\% (or 37\% if that man was also unmarried). This compares to a predicted probability of posting a comment of roughly $24 \%$ for men who were employed and married. While the same relationships exist in the 2010 dataset, the predicted probabilities have increased for all of the examined populations [31]. Perhaps this is related to an increased use of comment sections more generally. This is evidenced by the fact that the percentage of all respondents claiming to post comments changed from 11\% in 2008 to approximately $24 \%$ in 2010.

A third cross-sectional sample taken from 2012 showed a change in this pattern of the most likely posting occurring among unemployed, unmarried men. See Table 3 for the results of the logistic regression model examining the 2012 sample.

Table 3. Logistic regression evaluating which individuals are most likely to post online comments in 2012 (Pew Internet \& American Life Project [33]).

\begin{tabular}{lc}
\hline Independent Variables & Coefficient (Standard Errors) \\
\hline Age & $-0.02(0.00)^{* *}$ \\
Gender & $0.20(0.13)$ \\
Married & $-0.03(0.16)$ \\
Parent & $0.02(0.15)$ \\
Employment & $-0.14(0.15)$ \\
Party Identification & $-0.03(0.09)$ \\
Religious Attendance & $-0.04(0.04)$ \\
Education & $0.16(0.05)^{* *}$ \\
Race & $0.46(0.19)^{*}$ \\
Income & $0.05(0.03)$ \\
Constant & $-1.98(0.39)^{* *}$ \\
\hline Model Summary Statistics & \\
Number of Observations & 1456 \\
Pseudo R-Squared & 0.04 \\
Log Likelihood & -732.86 \\
\hline
\end{tabular}

Notes: The dependent variable is a binary variable where 1 indicates that the respondent did comment on a website and 0 indicates that the respondent did not comment on any website; $\mathrm{N}=970,{ }^{*}=p<0.05,{ }^{* *}=p<0.01$.

In 2012, there is a shift in the demographic characteristics of those individuals most likely to comment. No longer are gender, employment, or marital status related to one's probability of posting. The 2012 data suggests that race, age, and educational achievement are more predictive of whether or not a respondent has posted in relation to a political issue [33]. In terms of age, younger Americans are

1 The dependent variable in this regression is slightly different than the one used in the 2008 regression. Specifically, the 2008 variable measures whether the respondent posted a comment on any website such as an online news site whereas the 2010 variable is specific to whether or not the respondent posted a comment on an online news article. 
substantially more likely to post comments than their older counterparts. For example, a respondent who is the age of 18 has a $36 \%$ probability of posting. This drops precipitously as those 49 have a $21 \%$ probability. Likewise, a 70 -year-old has a $13 \%$ probability of sharing thoughts or opinions through these online forums. For race, it appears as if white Americans are 6\% more likely to post than those who identify as nonwhite ( $22 \%$ to $15 \%)$. Finally, it appears as if educational attainment is positively correlated with posting on comment sections. In other words, the more educated the individual the more likely he or she is to have posted. Moving from having a high school education to having an education at the postgraduate or professional level increases the probability of posting from $16 \%$ to $27 \%$.

\section{Political Participation}

The 2012 dataset provides an interesting series of questions that are helpful in analyzing another facet of the lives of online commenters [33]. This information was not available in the earlier years of data collection. An activism scale was created for this paper from a series of variables all speaking to the propensity for the individual respondent to get involved politically, either locally or nationally. This scale includes whether the respondent: attended a political rally or speech, attended an organized protest, attended a political meeting on local town or school affairs, worked or volunteered for a party or candidate, served as a member of a group (not a political party) influenced policy or government, worked with citizens to solve a community problem, and/or contributed money to a candidate, party, or political organization in the past twelve months. The Cronbach's alpha coefficient for this scale is 0.71 which demonstrates a moderate, but statistically acceptable, covariance between the variables.

In Table 4, an ordinary least squares (OLS) regression produced evidence of a significant relationship between posting on comment sections and being more active politically. Participants who indicated that they have a history of posting on comment sections were also more likely to have been politically active in at least one of the ways described above.

Table 4. Ordinary Least Squares (OLS) regression analyzing the connection between posting to online comment sections and engaging in political activity [33].

\begin{tabular}{lc}
\hline Independent Variables & Coefficient (Standard Errors) \\
\hline Age & $0.00(0.00)^{* *}$ \\
Gender & $0.01(0.01)$ \\
Comment Section & $0.15(0.01)^{* *}$ \\
Married & $-0.02(0.01)$ \\
Parent & $0.02(0.01)$ \\
Employment & $-0.01(0.01)$ \\
Party Identification & $0.02(0.01)^{* *}$ \\
Religious Attendance & $-0.02(0.00)^{* *}$ \\
Education & $0.02(0.00)^{* *}$ \\
Race & $0.01(0.02)$ \\
Income & $0.01(0.00)^{*}$ \\
Constant & $-1.98 * *(0.59)$ \\
\hline Model Summary Statistics & \\
Number of Observations & 1456 \\
Adjusted R-Squared & 0.13 \\
\hline
\end{tabular}

Notes: The dependent variable is a scale based on a series of variables attempting to gauge the level of political involvement of the respondent; $\mathrm{N}=970,{ }^{*}=p<0.05,{ }^{* *}=p<0.01$.

Unfortunately, the 2008 and 2010 datasets are focused almost exclusively on online political behavior and, consequently, do not contain similar variables to make a cross-election comparison. However, the 2012 results provide some reason to avoid alarmist language about the content of online conversations. Even with the limitations on the data, it is interesting to note that even controlling for income, gender, race, education, employment, and other demographic differences that comment 
sections are still correlated with offline political activity. There appears to be something unique about involvement on these forums.

\section{Discussion}

This study aimed to identify demographic factors predicting online posting to comment sections and whether being politically active online was related to being politically active offline (in national or local politics). A pattern of results demonstrated that, indeed, there are certain groups of people who are more likely to post to comment sections. Specifically, in 2008 and 2010, unemployed, unmarried men were the group most likely to be using online comment sections.

Between 2008 and 2012 there has been a 9\% increase in the number of individuals posting to online comment sections (from $11 \%$ to $20 \%$ ). Given this change, it is no wonder that, demographically, commenters now look very different than they did 8 years ago. This same change is consistent with other forms of new media. For example, relative to 8 years ago, individuals of all age, class, and racial groups are more likely to have a Facebook or Twitter page [34]. As online Internet users increase it is clear that, relative to the past, individuals are less socially isolated and appear to be actively involved in a host of political activities.

Commenters are significantly more likely to engage in real, meaningful ways with the politics of their communities and their nation relative to those who do not post. However, it is not possible to determine the direction of the relationship. In other words, does posting to these online forums produce feelings of politically efficacy and increase involvement? Or, do those who are already inclined to be involved politically take advantage of both offline and online opportunities to discuss politics? Either way, these results seem to suggest that comment sections are not simply venues for the alienated and uninvolved. The caricature of online commenters as so-called "trolls" enticed by the protective anonymity of online forums that can allow them to spew forth all sorts of negative rhetoric may be overly simplistic and possibly based more on anecdotes than on evidence.

However, the picture is not all rosy. While in the past, comment sections seemed like a refuge for those disaffected by politics, today these forums are dominated by wealthy, white, well-educated individuals. This supports Erouen's argument that online forums can serve to exacerbate the existing hierarchies in American society [22]. If we want the Internet to serve as a truly democratic tool, then it cannot simply replicate the existing, offline power differentials that marginalize poor and minority individuals in the political process.

Likewise, the findings pose a curious question: what happened to the unmarried, unemployed men from 2008 and 2010? Optimistically, economic conditions have improved in the country over the time period studied and perhaps trends such as this have contributed to a decrease in the isolation of these individuals. Pessimistically, it is possible that the increased use of comment sections has hidden the voices of this marginalized sect. If driven from comment sections, have these individuals found a home somewhere else? These questions deserve more time and attention than they have found here. Indeed, populist movements in the United States and in other parts of the world suggest that you do not want to ignore a large swath of angry, disaffected individuals.

Comment sections are becoming an increasingly attractive tool for those active in politics. Indeed, approximately a fourth of all American citizens have taken part, at some point, in a conversation occurring on one of these forums. To put this in context, in many states there are likely to be more individuals having conversations on comment sections than will vote in presidential primaries or caucuses. That being the case, comment sections are an area of tremendous political activity and warrant more attention in the literature. Specifically, experimental research could be helpful in illuminating the ways in which long-term exposure to comment sections shape the way that readers understand and interact with politics.

As noted at the outset, this discussion occurs within the larger debate about the role of the Internet in American politics. The findings suggest that there might be some evidence that Hindman was correct in arguing that discussions online are controlled by elites [10]. However, comment sections are 
only one part of this discussion. In order to more fully understand the role of the Internet in shaping attitudes and behaviors as they relate to American politics, research needs to continue to isolate ways in which online discussions are different from offline discussions and rigorously test the effect of these differences.

It is easy to laugh at the caricature of online commenters-socially awkward, angry, etc. However, the research does not support this characterization. In fact, these results indicate that commenters are elite, privileged, and politically active. At the very least, these findings suggest that anecdotes are not sufficient in describing the political debates occurring on these forums. As individuals increasingly make their way to these comment sections, it is imperative that the research follows them there.

Conflicts of Interest: The author declares no conflict of interest.

\section{Appendix A}

Table A1. Summary of variables used during the 2008 regression analyses.

\begin{tabular}{|c|c|c|}
\hline Variable & Label & Coding \\
\hline Comment & $\begin{array}{l}\text { Did R comment on a website of any } \\
\text { kind, such as political or news site? }\end{array}$ & $0=$ No; $1=$ Yes \\
\hline Age & R's age category & $1=18-31 ; 2=32-43 ; 3=44-53 ; 4=54-62 ; 5=63-71 ; 6=72+$ \\
\hline Race & $\mathrm{R}^{\prime} \mathrm{s}$ race & $0=$ Other $; 1=$ White \\
\hline Republican & Is $\mathrm{R}$ a Republican & $0=$ No; $1=$ Yes \\
\hline Democrat & Is $\mathrm{R}$ a Democrat & $0=$ No; $1=$ Yes \\
\hline Gender & R's gender & $0=$ Female $; 1=$ Male \\
\hline Employment & Is R employed or retired & $\begin{array}{l}0=\text { Not employed } ; 1=\text { employed or retired } \\
1=\text { Less than } \$ 10,000 ; 2=\$ 10,000-\$ 20,000 ; 3=\$ 20,000-\$ 30,000\end{array}$ \\
\hline Income & $\mathrm{R}^{\prime} \mathrm{s}$ income category & $\begin{array}{l}4=\$ 30,000-\$ 40,000 ; 5=\$ 40,000-\$ 50,000 ; 6=\$ 50,000-\$ 75,000 \\
7=\$ 75,000-\$ 100,000 ; 8=\$ 100,000-\$ 150,000 ; 9=\$ 150,000+\end{array}$ \\
\hline Married & $\mathrm{R}^{\prime} \mathrm{s}$ marital status & $0=$ Not married; $1=$ Married \\
\hline Parent & $\mathrm{R}^{\prime}$ s parental status & $0=$ Not a parent; $1=$ Yes, a parent \\
\hline Religious Attendance & $\mathrm{R}^{\prime} \mathrm{s}$ religious attendance & $\begin{array}{l}1=\text { Never } ;=\text { Seldom; } 3=\mathrm{A} \text { few times a year; } 4=\text { Once or } \\
\text { twice a month; } 5=\text { Once a week; } 6=\text { More than once a week }\end{array}$ \\
\hline Education & $\mathrm{R}^{\prime}$ s level of education & $\begin{array}{l}1=\text { None, or grades } 1-8 ; 2=\text { High school incomplete (grades } \\
9-11 \text { ); } 3=\text { High school graduate; } 4=\text { Technical, trade, or } \\
\text { vocational school; } 5=\text { Some college, no four year degree; } \\
6=\text { College graduate; } 7 \text { = Post-graduate training } / \text { professional }\end{array}$ \\
\hline
\end{tabular}

Source: Pew Internet and American Life Project 2008 [32].

For 2010, an attempt was made to use the same variables although changes in question wording and survey design made an exact replication impossible. However, the similarity in the results between the two years suggests that there was a strong correlation between the old and new surveys. The proceeding variables were used as part of the 2010 analyses.

Table A2. Summary of variables used during the 2010 regression analyses.

\begin{tabular}{lll}
\hline Variable & Label & Coding \\
\hline Comment & Did R ever comment on a news & $0=$ No; $1=$ Yes \\
story or blog online? & R's actual age \\
Age & R's age & $0=$ Other; $1=$ White \\
Race & R's race & $0=$ No; $1=$ Yes \\
Republican & Is R a Republican & $0=$ No; $1=$ Yes \\
Democrat & Is R a Democrat & $0=$ Female; $1=$ Male \\
Gender & R's gender & $0=$ Not employed; $1=$ employed or retired \\
Employment & Is R employed or retired & $1=$ Less than $\$ 10,000 ; 2=\$ 10,000-\$ 20,000 ; 3=\$ 20,000-\$ 30,000 ;$ \\
& & $4=\$ 30,000-\$ 40,000 ; 5=\$ 40,000-\$ 50,000 ; 6=\$ 50,000-\$ 75,000 ;$ \\
Income & R's income category & $7=\$ 75,000-\$ 100,000 ; 8=\$ 100,000-\$ 150,000 ; 9=\$ 150,000+$ \\
& & $0=$ Not married; $1=$ Married \\
Married & R's marital status & $0=$ Not a parent; $1=$ Yes, a parent \\
Parent & $R^{\prime}$ s parental status & $1=$ None, or grades $1-8 ; 2=$ High school incomplete; $3=$ High school \\
& & graduate; $4=$ Technical, trade, or vocational school; $5=$ Some college, \\
Education & R's education level & no four year degree; $6=$ College graduate; $7=$ Post-graduate \\
& & training/professional \\
\hline
\end{tabular}


Likewise for 2012, an attempt was made to use the same variables, although changes in question wording and survey design made an exact replication impossible. However, the similarity in the results between the 2 years suggests that there was a strong correlation between the old and new surveys. The proceeding variables were used as part of the 2012 analyses.

Table A3. Summary of variables used during the 2012 regression analyses.

\begin{tabular}{|c|c|c|}
\hline Variable & Label & Coding \\
\hline Comment & $\begin{array}{l}\text { Did R comment on online news } \\
\text { story or blog about a political issue? }\end{array}$ & $0=$ No; $1=$ Yes \\
\hline Age & R's age & R's actual age \\
\hline Race & $\mathrm{R}^{\prime}$ s race & $0=$ Other $; 1=$ White \\
\hline Party Identification & $\mathrm{R}^{\prime}$ s party identification & $1=$ Republican; 2 = Independent; $3=$ Democrat \\
\hline Gender & $\mathrm{R}^{\prime}$ s gender & $0=$ Female $; 1=$ Male \\
\hline Employment & Is R employed & $\begin{array}{l}0=\text { Not employed } 1=\text { Employed } \\
1=\text { Less than } \$ 10,000 ; 2=\$ 10,000-\$ 20,000 ; 3=\$ 20,000-\$ 30,000 ; \\
4=\$ 30,000-\$ 40,000 ; 5=\$ 40,000-\$ 50,000 ; 6=\$ 50,000-\$ 60,000 ;\end{array}$ \\
\hline Income & $\mathrm{R}^{\prime}$ s income category & $\begin{array}{l}7=\$ 60,000-\$ 75,000 ; 8=\$ 75,000-\$ 100,000 \\
9=\$ 100,000-\$ 15,000 ; 10=\$ 150,000-\$ 250,000 \\
11=\$ 250,000-\$ 500,000 ; 12=\$ 500,000+\end{array}$ \\
\hline Married & R's marital status & $0=$ Not married $; 1=$ Married \\
\hline Parent & $\mathrm{R}^{\prime}$ s parental status & $0=$ Not a parent; $1=$ Yes, a parent \\
\hline Education & $\mathrm{R}^{\prime}$ s education level & $\begin{array}{l}1=\text { None } \text {, or grades } 1-8 ; 2=\text { High school incomplete } 3=\text { High } \\
\text { school graduate } 4=\text { Technical, trade, or vocational school; } \\
5=\text { Some college, no four year degree; } 6 \text { = College graduate; } \\
7=\text { Post-graduate training } / \text { professional }\end{array}$ \\
\hline
\end{tabular}

Source: Pew Internet and American Life Project 2012 [33].

\section{References}

1. Saturday Night Live. “Season 37: Episode 2 Melissa Mccarthy/Lady Antebellum.” 1 October 2011. Available online: https:/ / www.nbc.com/saturday-night-live/season-37/episode/2-melissa-mccarthy-with-ladyantebellum-57956 (accessed on 21 October 2016).

2. Artime, Michael. "Encouraging engagement: Attracting students to online political activism." 2015. Available online: https: / / wpsa.research.pdx.edu/papers/docs/Artime\%20Encouraging\%20Engagement $\% 20$ WPSA $\%$ 202015.docx (accessed on 20 October 2016).

3. Castells, Manuel. The Rise of the Network Society: The Information Age: Economy, Society and Culture. New York: Wiley, 2000.

4. $\quad$ Buss, Terry F., and Nathaniel J. Buss. "The internet, politics, and democracy." In Modernizing Democracy: Innovations in Citizen Participation. Edited by Terry F. Buss, F. Stevens Redburn and Kristina Guo. Armonk: M.E. Sharpe, 2006.

5. Sunstein, Cass. Republic.Com 2.0. Princeton: Princeton University Press, 2009.

6. Hasell, Ariel, and Brian E. Weeks. "Partisan provocation: The role of partisan news use and emotional responses in political information sharing in social media." Human Communication Research 42 (2016): 641-61. [CrossRef]

7. Hwang, Hyunseo, Youngju Kim, and Catherine U. Huh. "Seeing is believing: Effects of uncivil online debate on political polarization and expectations of deliberation." Journal of Broadcasting E Electronic Media 58 (2014): 621-33. [CrossRef]

8. Lelkes, Yphtach, Gaurav Sood, and Shanto Iyengar. "The hostile audience: The effect of access to broadband internet on partisan affect." American Journal of Political Science (2015): 1-16. [CrossRef]

9. Morozov, Evgeny. The Net Delusion: The Dark Side of Internet Freedom. New York: Public Affairs, 2011.

10. Hindman, Matthew. The Myth of Digital Democracy. Princeton: Princeton University Press, 2008.

11. Wellman, Barry, Anabel Quan Haase, James Witte, and Keith Hampton. “Does the internet increase, decrease, or supplement social capital? Social networks, participation, and community commitment." American Behavioral Scientist 45 (2001): 436-55. [CrossRef]

12. Boulianne, Shelley. "Does internet use affect engagement? A meta-analysis of research." Political Communication 26 (2009): 193-211. [CrossRef]

13. Mossberger, Karen, Yonghong Wu, and Jared Crawford. “Connecting citizens and local government? Social media and interactivity in major U.S. Cities." Government Information Quarterly 30 (2013): 351-58. [CrossRef] 
14. Tedesco, John C. "Political information efficacy and internet effects in the 2008 U.S. Presidential election." American Behavioral Scientist 55 (2011): 696-713. [CrossRef]

15. Freelon, Deen. "Discourse architecture, ideology, and democratic norms in online political discussion." New Media E Society 17 (2015): 772-91. [CrossRef]

16. Rosenberry, Jack. "Users support online anonymity despite increasing negativity." Newspaper Research Journal 32 (2011): 6-19.

17. Rowe, Ian. "Civility 2.0: A comparative analysis of incivility in online political discussion." Information, Communication, and Society 18 (2015): 121-38. [CrossRef]

18. Ziegele, Marc, Timo Breiner, and Oliver Quiring. "What creates interactivity in online news discussions? An exploratory analysis of discussion factors in user comments on news items." Journal of Communication 64 (2014): 1111-38. [CrossRef]

19. Blom, Robin, Serena Carpenter, Brian J. Bowe, and Ryan Lange. "Frequent contributors within U.S. Newspaper comment forums: An examination of their civility and information value." American Behavioral Scientist 58 (2014): 1314-28. [CrossRef]

20. Rösner, Leonie, and Nicole C. Krämer. "Verbal venting in the social web: Effects of anonymity and group norms on aggressive language use in online comments." Social Media E Society, 2016. [CrossRef]

21. Hsueh, Mark, Kumar Yogeeswaran, and Sanna Malinen. "'Leave your comment below': Can biased online comments influence our own prejudicial attitudes and behaviors?" Human Communication Research 41 (2015): 557-76. [CrossRef]

22. Erouen, Maria. "Moral argumentation as a rhetorical practice in popular online discourse: Examples from online comment sections as celebrity gossip." Discourse E Communication 8 (2014): 278-98. [CrossRef]

23. Shepherd, Tamara, Alison Harvey, Tim Jordan, Sam Srauy, and Kate Miltner. "Histories of hating." Social Media E Society 1 (2015): 1-10. [CrossRef]

24. James, Carrie, Katie Davis, Andrea Flores, John M. Francis, Lindsay Pettingill, Margaret Rundle, and Howard Gardner. "Young people, ethics, and the new digital media." Contemporary Readings in Law E Social Justice 2 (2011): 215-84.

25. Flanagin, Andrew J., and Miriam J. Metzger. "Digital media and youth: Unparalleled opportunity and unprecedented responsibility." In Digital Media, Youth, and Credibility. Edited by Miriam J. Metzger and Andrew J. Flanagin. Cambridge: The MIT Press, 2008, pp. 5-28.

26. Jacobson, Harris. "Challenges to teaching credibility assessment in contemporary schooling." In Digital Media, Youth and Credibility. Edited by Miriam J. Metzger and Andrew J. Flanagin. Cambridge: The MIT Press, 2008.

27. Weingarten, Fred W. “Credibility, politics, and public policy.” In Digital Media, Youth, and Credibility. Edited by Miriam J. Metzger and Andrew J. Flanagin. Cambridge: The MIT Press, 2008.

28. Hoffman, Karen S. "Comment forum speech as a mirror of mainstream discourse." In Controlling the Message: New Media in American Political Campaigns. Edited by Victoria A. Farrar-Myers and Justin S. Vaughn. New York: New York University Press, 2015, pp. 221-44.

29. Singer, Jane B. "Norms and the network: Journalistic ethics in a shared media space." In Journalism Ethics: A Philosophical Approach. Edited by Christopher Meyers. Oxford: Oxford University Press, 2010, pp. 117-30.

30. Graham, Todd, and Scott Wright. "A tale of two stories from 'below the line': Comment fields at the guardian." The International Journal of Press/Politics 20 (2015): 317-38. [CrossRef]

31. Pew Research Center. "November 3-24, 2010-Post Election." Available online: http://www.pewinternet. org/datasets/november-2010-post-election/ (accessed on 8 February 2011).

32. Pew Research Center. "November 20-December 4, 2008-Post Election." Available online: http://www. pewinternet.org/2009/04/15/the-internets-role-in-campaign-2008/ (accessed on 27 January 2011).

33. Pew Research Center. "July 16-August 7, 2012-Civic Engagement." Available online: http://www. pewinternet.org/datasets/august-2012-civic-engagement/ (accessed on 19 May 2016).

34. Gottfried, Jeffrey, and Elisa Shearer. "News Use across Social Media Platforms 2016." Available online: http:/ /www.journalism.org/2016/05/26/news-use-across-social-media-platforms-2016/ (accessed on 30 June 2016).

(C) 2016 by the author; licensee MDPI, Basel, Switzerland. This article is an open access article distributed under the terms and conditions of the Creative Commons Attribution (CC-BY) license (http://creativecommons.org/licenses/by/4.0/). 